\title{
Psychological violence against pregnant women in a prenatal care cohort: rates and associated factors in São Luís, Brazil
}

Marizélia Rodrigues Costa Ribeiro ${ }^{1}$, Antônio Augusto Moura da Silva², Maria Teresa Seabra Soares de Britto e Alves², Rosângela Fernandes Lucena Batista², Lourdes Maria Leitão Nunes de Rocha ${ }^{3}$, Lilia Blima Schraiber ${ }^{4}$, Nilzângela Lima Medeiros ${ }^{5}$, Danielle Cristina Silva Costa ${ }^{6}$, Heloisa Bettiol ${ }^{7}$ and Marco Antônio Barbieri ${ }^{7 *}$

\begin{abstract}
Background: Violence against pregnant women has been associated with gestational and perinatal disorders. Psychological violence is the type least investigated and its associated factors have been little studied. The present study was conducted in order to estimate prevalence rates and analyze the factors associated with exclusive and recurrent psychological violence in the municipality of São Luís, Brazil.

Methods: Data regarding 982 pregnant women, aged from 14 to 45 years, interviewed in 2010 and 2011 in a prenatal cohort were used. A self-applied questionnaire was used to screen for violence. Pregnant women submitted to physical and sexual violence were excluded from the analysis of factors associated with exclusive psychological violence. Prevalence ratios and 95\% confidence intervals were estimated by a Poisson regression model with a hierarchical approach at three levels. At level 1 of the theoretical-conceptual model, we analyzed demographic and socioeconomic characteristics and variables that express gender inequalities; at level 2, we analyzed social support received by the women, and at level 3, the life experiences of the pregnant women.

Results: Prevalence rate of exclusive psychological violence was $41.6 \%$ and of recurrent violence was $32.6 \%$. Exclusive psychological violence was associated with pregnant women's age of 14 to 18 years (PR: 1.32 95\% Cl: 1.04 - 1.70), pregnant women's schooling superior to that of her intimate partner (PR: 1.54 95\% Cl: $1.09-2.16$ ), inadequate social affective support/positive social interaction (PR: $1.3495 \% \mathrm{Cl}: 1.11-1.62$ ), use of illicit drugs by the pregnant women (PR: 1.80 95\% Cl: 1.16 - 2.81) and having had six or more intimate partners in life (PR: 1.52 95\% Cl: 1.18 - 1.96). Recurrent exclusive psychological violence was associated with inadequate social affective support/ positive social interaction (PR: 1.47 95\% Cl: 1.15 - 1.87), use of illicit drugs by the pregnant women (PR: 2,28 95\% Cl: 1,40 - 3,71) and having had six or more intimate partners in life (PR: 1.47 95\% Cl: $1.06-2.03$ ).
\end{abstract}

Conclusions: Psychological violence was a common phenomenon in this population of pregnant women that was associated with gender inequalities, inadequate social support and illicit drug use and should be routinely investigated during prenatal visits at health care services.

Keywords: Prenatal care, Gender and health, Pregnant women, Violence against women, Domestic violence

\footnotetext{
* Correspondence: mabarbieri@fmrp.usp.br

${ }^{7}$ Faculty of Medicine of Ribeirão Preto, University of São Paulo, São Paulo, Brazil

Full list of author information is available at the end of the article
} 


\section{Background}

The expression violence against women has been defined as any gender-based action or conduct that causes death or physical, sexual or psychological damage to women both in public and private spheres [1].

Any act of violence against women must be considered as a violation of human rights and as a public health problem [2]. In addition to physical injuries and sexually transmitted diseases, which can be more easily imputed to aggression, other disorders such as depression, suicide, drug abuse, delayed beginning of prenatal care and preterm birth have been associated with maltreatment of women [3].

Violence against pregnant women seems to be more prevalent than diseases routinely investigated during prenatal care, such as pre-eclampsia and diabetes [4]. Literature reviews have shown rates ranging from $0.9 \%$ to $57.1 \%$ depending on the choice of methods and on sociocultural conditions [4-7]. In Brazil, the prevalence rates detected by researchers of the Multi-Country Study of the World Health Organization were $8 \%$ for the city of São Paulo and $11.1 \%$ for the Wooded Zone of Pernambuco [3]. Taillieu and Brownridge [4] stated that maltreatment of pregnant women was recurrent in successive pregnancies.

During the gestational period, rates and risk factors for psychological violence (more frequent than physical or sexual violence) have been less investigated $[4,8]$, perhaps because the instrument more frequently used for screening, the Abuse Assessment Screen, only permits a detailed investigation of physical violence during pregnancy $[4,9]$.

Prevalence rates of psychological violence during pregnancy ranged from $1.5 \%$ to $43.2 \%$. The highest was detected in Pakistan [4]. Prevalence rate of psychological violence on the part of intimate partners on the African continent was $24.8 \%$ (Uganda), $41 \%$ (a public hospital in South Africa) and 49\% (a rural community in South Africa) [7].

In Brazil, the highest rate (61.7\%) was detected in puerperae admitted to the three major public maternities of Rio de Janeiro [10]. In the Multi-country study, psychological violence on the part of the intimate partner was the most frequent $(28.8 \%)$, followed by physical (11.6\%) and sexual violence (5.6\%) [11].

Regarding the factors associated with violence during pregnancy, Tailleu and Brownridge [4] called attention to the fact that the analyses were almost always limited to the bivariate stage. A previous history of violence was pointed out by these researchers as one of the strongest predictors. Divorced/separated women were found to be at higher risk, even when confounding factors were controlled for, such as women who smoked, ingested alcohol and/or took illicit drugs [4]. Associations between violence during pregnancy and age range, race/ethnic group, educational level, remunerated job of the pregnant woman and of her intimate partners and family income yielded inconclusive results [4].

In Brazil, only one study investigated factors associated with domestic psychological violence during pregnancy. Pregnant women with up to eight years of schooling, economically responsible for the family, with common mental disorder and who had witnessed or suffered physical aggression before 15 years of age, who had intimate partners up to the age of 19 years and who ingested alcohol two or more times per week were at higher risk of suffering psychological violence [12]. The authors did not report whether they had included in their analysis pregnant women submitted also to other types of violence.

The present study was conducted in order to investigate the prevalence rate of psychological violence against pregnant women seen at prenatal care services in the municipality of São Luís, Brazil and to analyze factors associated with exclusive psychological violence (EPV) and recurrent exclusive psychological violence (REPV).

\section{Methods}

From February 2010 to June 2011, 1446 pregnant women were interviewed in phase one (prenatal) of a cohort investigating new etiological factors for preterm birth in the municipality of São Luís (Maranhão/Brasil), which is part of the Brazilian Birth Cohort Studies of Ribeirão Preto and São Luís (Brisa).

Data was obtained in a convenience sample. It was impossible to draw a random sample of the population of pregnant women in São Luís because there was no list available. The inclusion criteria were: having performed the first ultrasound exam at less than 20 weeks of gestational age and to intend to give birth at one of the maternities in the municipality. Pregnant women carrying more than one fetus were not included.

Pregnant women attending prenatal care clinics of three public maternity hospitals and services of obstetric ultrasonography were invited to participate in an interview to be held at 22 to 25 weeks of gestational age.

In the analysis of factors associated with EPV, a minimum number of 948 women interviewed would be necessary. This sample size considered a $5 \%$ probability of type I error, $80 \%$ statistical power and prevalence of psychological violence against pregnant women of $11.1 \%{ }^{3}$ (estimate based on the Multi-country study of the WHO, in the Wooded Zone of Pernambuco, Brazil).

To determine the prevalence rate of EPS, we excluded 199 pregnant women submitted also to physical and sexual abuse and four women who did not respond to one or more screening questions for these two types of violence. To determine the prevalence rates of REPV, i.e., abuse occurring on more than one occasion, we excluded women submitted to EPV on only one occasion. 
After the additional exclusion of 295 pregnant women who did not live with their intimate partners, the effective sample size was 982 .

For the investigation of the factors associated with recurrent abuse, we excluded an additional 184 pregnant women who had been submitted to EPV only once, resulting in 1078 women.

Before the application of the questionnaire, the pregnant women gave written informed consent to participate in the study. When they were younger than 18 years, an accompanying adult also signed the consent form. It was explained to all women that the Brisa prenatal cohort was investigating possible causes of preterm birth, such as violence against pregnant women, and that confidentiality, image protection and non-stigmatization were guaranteed to all of them.

Data of interest were selected from a database containing information of the Self-Applied Prenatal Questionnaire and of the Prenatal Interview Questionnaire. Data about violence, social support and use of illicit drugs by the interviewees were obtained from the self-applied questionnaire. Some demographic, socioeconomic and behavioral characteristics of the pregnant women were obtained from the second questionnaire, in addition to life aspects of the intimate partners residing with the interviewees and of the family heads. The skin color variable was obtained from the Birth Questionnaire.

For the screening of psychological violence, we used the instrument of the Multi-country study on women's health and violence against women of the WHO. The instrument Social Support Scale of the Medical Outcomes Study (MOS) was used to investigate the material dimension and the groups of affective/positive social interaction and emotional information. The two instruments have been validated for Brazil $[13,14]$.

Psychological violence was considered to have occurred when the interviewee responded affirmatively to one of the four following questions: during this pregnancy, did anybody at any time a) Insult you or make you feel bad about yourself? b) Belittle of humiliate you in front of other persons? c) Do something to scare and intimidate you on purpose? d) Threaten to hurt you or somebody you like?

In the maternity hospitals of São Luís, 1379 puerperae of the cohort were interviewed a second time on the occasion of the birth of their children. Characteristics of the life of the women and their relatives and intimate partners were obtained, as well as data about childbirth and the neonate, born alive or stillborn. The data of the women who were not interviewed at the time of delivery were obtained at their home in case they were located. The chronological age of the pregnant women ranged from 14 to 45 years.

The theoretical-conceptual model was hierarchized at three levels. Level 1 included variables expressing demographic and socioeconomic characteristics and gender inequalities: a) age range of the pregnant woman and of her residing intimate partner (up to 19 years, 20 to 24 years or 25 years or more); b) self-reported skin color of the pregnant woman (white, black, crossbred mixed/mulatto/cabocla/brown - or yellow/oriental); c) educational level of the pregnant woman and of her residing intimate partner (elementary, middle or higher); d) remunerated job of the pregnant woman (no or yes); e) family income in minimum wages (less than 1,1 to less than 3, 3 to less than 5 , or 5 or more); f) Brazilian economic classification (classes $\mathrm{A} / \mathrm{B}, \mathrm{C}$ or $\mathrm{D} / \mathrm{E}$, with classes $\mathrm{A}$ and $\mathrm{B}$ having the highest educational level and owning more consumer goods, class $\mathrm{C}$ being intermediate, and classes D and $\mathrm{E}$ having the lowest educational level and being the poorest) [15]; g) differences in schooling and occupation between the pregnant women and their residing intimate partners (no difference, pregnant women with higher schooling or better occupation, or partners with higher schooling or better occupation); and h) who is the head of the family, i.e., the person with the highest income (pregnant woman, intimate partner, or somebody else).

Level 2 analyses involved variables that demonstrate the social support received by the pregnant women: material, emotional/information and affective/positive social interaction dimensions, with cut-off points in the 75th percentile (inadequate when lower than the 75 th percentile and adequate in the opposite case).

Level 3 variables express life experiences of the pregnant women. The following variables were selected: a) alcohol abuse (four or more doses on a single occasion) during pregnancy (yes or no); use of illicit drugs during pregnancy and/or up to 3 months before it (yes or no); c) smoking during pregnancy (yes or no); and d) number of male partners with whom the pregnant women had sex relations during life (1, 2 to 5 or 6 or more intimate partners) (Figure 1).

Descriptive analysis was used to present frequencies and percentages. The Poisson regression model with robust adjustment of variance was used to investigate the associations between independent variables and outcomes because the prevalence rates of violence detected were higher than $10 \%$.

The independent variables with a p-value of less than 0.2 in bivariate analysis were selected for adjusted analysis in each level of the hierarchical model. The category of the variable with the lowest percentage of violence was considered as reference. Prevalence ratio (PR) and its 95\% confidence interval were used for the analysis of associated factors. Level 1 variables were first adjusted to each other and the variables with a P-value of less than 0.10 were selected for inclusion in the subsequent level. Level 2 variables plus the variables with a $\mathrm{P}<0.10$ value in the 


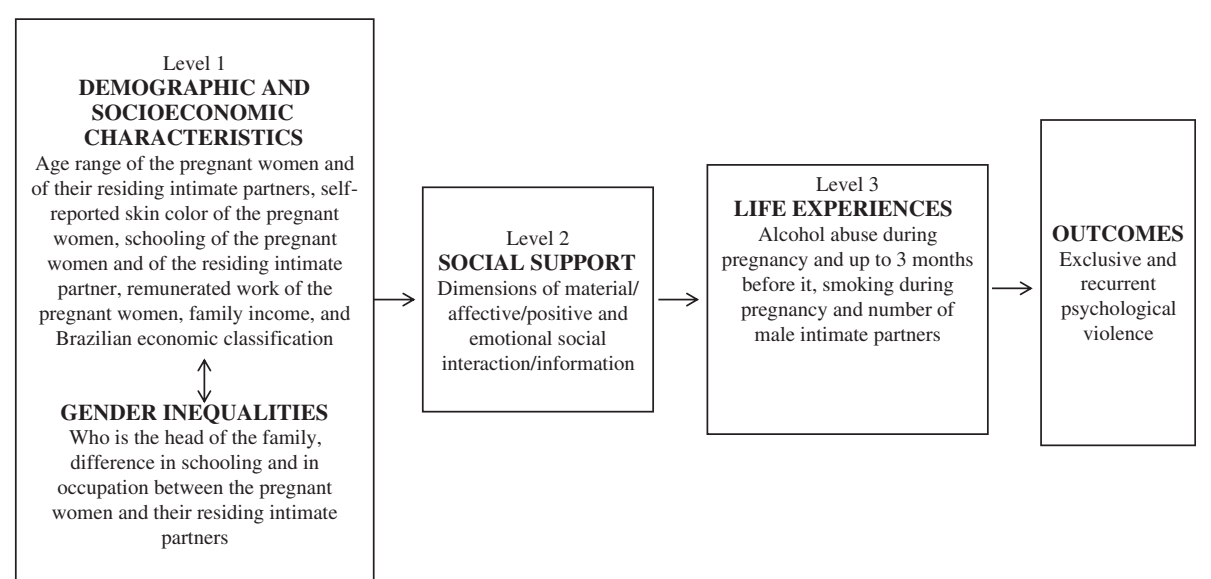

Figure 1 Hierarchical model for the assessment of factors associated with psychological violence.

previous level were then adjusted simultaneously. Finally, level 3 variables plus variables with a $P<0.10$ value in the previous levels were then adjusted simultaneously. The significance of each variable was considered at the level to which it belonged.

The investigation reported in the present paper fulfilled the requirements of Resolution 196/96 of the National Health Council and its complementary norms and was approved by the Research Ethics Committee of the University Hospital of the Federal University of Maranhão (protocol no 4771/2008-30).

\section{Results}

EPV prevalence rate was $41.6 \%$ and REPV prevalence rate was $32.6 \%$.

With respect to EPV outcome, the results of the descriptive and bivariate analyses of gender inequalities, demographic and socioeconomic characteristics, social support received and life experiences are presented in Table 1.

In adjusted analysis, the following variables continued to be associated with EPV (Table 2): age of the pregnant woman of 14 to 19 years (PR: 1.32 95\% CI: $1.04-1.70$ ), higher educational level of the pregnant woman than that of her intimate partner (PR: 1.54, 95\% CI: 1.09 2.16), inadequate affective social support/positive social interaction (PR: 1.34, 95\% CI: 1.11 - 1.62), use of illicit drugs by the pregnant woman (PR: 1.80, 95\% CI: 1.16 2.81 ), and having had six or more intimate partners in life (PR: 1.52, 95\% CI: 1.18 - 1.96).

The results of the descriptive and bivariate analyses of REPV outcome are summarized in Table 3.

In the adjusted analysis, factors associated with REPV were: inadequate social affective support/positive social interaction (PR: 1.47 95\% CI: 1.15 - 1.87), use of illicit drugs by the pregnant woman (PR: 2.28
95\% CI: 1.40 - 3.71) and having had six or more intimate partners during life (PR: 1.47 95\% CI: 1.06 - 2.03) (Table 4).

\section{Discussion}

EPV prevalence rate was $41.6 \%$ and REPV prevalence rate was $32.6 \%$. Inadequate social affective support/positive social interaction, use of illicit drugs by the pregnant woman and having had six or more intimate partners during life were associated with both EPV and REPV. Being young or having higher educational level than their intimate partners were associated only with EPV.

Except for the results detected in the municipality of Rio de Janeiro (61.7\%) [10], in a rural community in South Africa (49\%) [16] and in the Southern Appalachians (79.8\%) [17], the prevalence rate of psychological violence (48.4\%) detected in the Brisa prenatal cohort was higher than those reported in other studies, which ranged from $1.5 \%$ to $43 \%$ [4,8,11,12,18-24]. EPV and REPV prevalence rates were lower than those reported in only four of these publications $[10,16,17,19]$.

These disparities can be attributed to methodological and sociocultural differences, as demonstrated in literature reviews about violence against pregnant women [5-7]. It should be pointed out that the general objective of the Brisa prenatal cohort was to investigate new etiological factors for preterm birth, with the violence against pregnant women being one of the factors investigated. Since violence was not the main study question, this may have facilitated reports of violence by the women.

Three hypotheses can explain these higher rates in the present study: a) the use of a self-applied instrument without the presence of the interviewer; b) the interviewees were constantly reminded of the impossibility of being identified in their responses; and c) violence during pregnancy was being investigated as a risk factor for 
Table 1 Bivariate analysis of the factors associated with exclusive psychological violence

\begin{tabular}{|c|c|c|c|c|c|}
\hline \multirow[b]{2}{*}{ Variables } & \multicolumn{5}{|c|}{ Exclusive psychological violence } \\
\hline & $n$ & $\%$ & $\mathrm{PR}^{*}$ & $95 \mathrm{Cl}^{* *}$ & $\mathrm{p}^{* * *}$ \\
\hline
\end{tabular}

Age range of the pregnant

women (years) $(n=1.243)$

$\begin{array}{llllll}25 \text { or more } & 696 & 38.7 & 1 & & \\ 20 \text { to } 24 & 393 & 45.0 & 1.16 & 1.01 & 1.34 \\ 14 \text { to } 19 & 154 & 45.4 & 1.17 & 0.96 & 1.43\end{array}$

Age range of the intimate partners (years, $n=1.001$ )

$\begin{array}{lccccc}25 \text { or more } & 734 & 37.6 & 1 & & \\ 20 \text { to } 24 & 242 & 42.1 & 1.12 & 0.94 & 1.33 \\ 14 \text { to } 19 & 25 & 48.0 & 1.28 & 0.84 & 1.94\end{array}$

Skin color of the pregnant women $(n=1.181)$

Crossbred
Black
White
Yellow/Oriental
Schooling of the pregnant
women ( $n=1.243$ )
Elementary
Middle
Higher

Schooling of the residing intimate partner $(n=982)$

$\begin{array}{lccccc}\text { Higher } & 79 & 36.7 & 1 & & \\ \text { Middle } & 728 & 37.7 & 1.03 & 0.76 & 1.39 \\ \text { Elementary } & 175 & 42.2 & 1.15 & 0.82 & 1.61\end{array}$

Remunerated job of the pregnant women $(n=1.243)$

$$
\begin{array}{llll}
\text { No } & 643 & 40.2 & 1 \\
\text { Yes } & 600 & 43.0 & 0.94
\end{array}
$$

Family income in minimum wages $(n=1.209)$

$$
\begin{aligned}
& <1 \\
& 1 \text { to }<3 \\
& 3 \text { to }<5 \\
& \geq 5
\end{aligned}
$$

Brazilian economic class $(n=1.186)$

$$
\begin{array}{llllll}
C & 811 & 40.4 & 1 & & \\
\text { D/E } & 178 & 43.2 & 1.07 & 0.89 & 1.29 \\
\text { A/B } & 197 & 44.1 & 1.09 & 0.91 & 1.30
\end{array}
$$

Who is the family head $(n=1.239)$

$$
\begin{array}{llllll}
\text { Partner } & 746 & 39.0 & 1 & & \\
\text { Pregnant woman } & 129 & 44.1 & 1.13 & 0.91 & 1.40
\end{array}
$$

\subsection{9}

0.094

0.072
Table 1 Bivariate analysis of the factors associated with exclusive psychological violence (Continued)

Others
Difference in schooling ( $\mathrm{n}=982)$
Pregnant woman $<$ residing
intimate partner
No difference
Pregnant woman $>$ residing
intimate partner
Difference in occupation $(\mathrm{n}=992)$
Pregnant woman $<$ residing
intimate partner
No difference
Pregnant woman $>$ residing
intimate partner
$\begin{array}{lllll}364 & 45.8 & 1.18 & 1.02 & 1.36\end{array}$

Material dimension of social support $<75$ th percentile $(n=1,243)$

0.001

$$
\begin{array}{llllll}
\text { No } & 378 & 34.3 & 1 & & \\
\text { Yes } & 865 & 44.7 & 1.30 & 1.11 & 1.52
\end{array}
$$

Positive affective/social interaction dimension of social support $<75^{\text {th }}$ percentile $(n=1.243)$

$$
\text { No }
$$$$
\text { Yes }
$$$$
\begin{array}{ccccc}
351 & 31.9 & 1 & & \\
892 & 45.4 & 1.42 & 1.20 & 1.68
\end{array}
$$

Emotional dimension/information of social support $<75$ th percentile $(n=1.243)$

$$
\begin{aligned}
& \text { No } \\
& \text { Yes }
\end{aligned}
$$

Level 3

Smoking during pregnancy $(n=1,243)$

$$
\begin{aligned}
& \text { No } \\
& \text { Yes }
\end{aligned}
$$

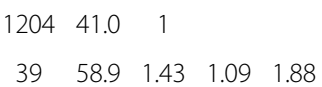

Use of illicit drugs up to 3 months before the current pregnancy $(n=1,240)$

$$
\begin{aligned}
& \text { No } \\
& \text { Yes }
\end{aligned}
$$$$
\begin{array}{lll}
1224 & 41.3 \quad 1
\end{array}
$$$$
\begin{array}{lllll}
16 & 68.7 & 1.66 & 1.19 & 2.33
\end{array}
$$

Alcohol abuse by the woman during pregnancy $(n=1,241)$

0.013

$$
\begin{aligned}
& \text { No } \\
& \text { Yes }
\end{aligned}
$$$$
\begin{array}{lll}
1129 & 40.5 \quad 1
\end{array}
$$$$
\begin{array}{lllll}
112 & 51.7 & 1.28 & 1.05 & 1.55
\end{array}
$$

Number of sex partners $(n=1.231)$

2 to 5

6 or more

$\begin{array}{lll}370 & 36.7 & 1\end{array}$

$\begin{array}{lllll}734 & 41.2 & 1.12 & 0.96 & 1.32\end{array}$

*Prevalence Ratio.

**95\% Confidence interval.

***P-value obtained by the likelihood ratio test based on the Poisson regression model.

São Luís-Brazil, 2010/2011. 
Table 2 Adjusted analysis of the factors associated with exclusive psychological violence

\begin{tabular}{|c|c|c|c|c|}
\hline \multirow{2}{*}{$\frac{\text { Variables }(\mathbf{n}=\mathbf{9 7 0})}{\text { Level } 1}$} & \multirow[t]{2}{*}{$\mathrm{PR}^{*}$} & \multicolumn{2}{|c|}{$95 \mathrm{Cl}^{* *}$} & \multirow[t]{2}{*}{$\mathrm{p}^{* * *}$} \\
\hline & & & & \\
\hline Age range of the pregnant women (years) & & & & 0.037 \\
\hline 25 or more & 1 & & & \\
\hline 20 to 24 & 1.18 & 0.99 & 1.40 & \\
\hline 14 to 19 & 1.32 & 1.04 & 1.70 & \\
\hline Difference in schooling & & & & 0.020 \\
\hline Pregnant woman $<$ residing intimate partner & 1 & & & \\
\hline No difference & 1.25 & 0.91 & 1.73 & \\
\hline Pregnant woman $>$ residing intimate partner & 1.54 & 1.09 & 2.16 & \\
\hline \multicolumn{5}{|l|}{ Level 2} \\
\hline $\begin{array}{l}\text { Positive affective/social interaction dimension of } \\
\text { social support }<75^{\text {th }} \text { percentile }\end{array}$ & & & & 0.002 \\
\hline No & 1 & & & \\
\hline Yes & 1.34 & 1.11 & 1.62 & \\
\hline \multicolumn{5}{|l|}{ Level 3} \\
\hline Smoking during pregnancy & & & & 0.066 \\
\hline No & 1 & & & \\
\hline Yes & 1.42 & 0.98 & 2.07 & \\
\hline $\begin{array}{l}\text { Use of illicit drugs up to three months before } \\
\text { the current pregnancy }\end{array}$ & & & & 0.009 \\
\hline No & 1 & & & \\
\hline Yes & 1.80 & 1.16 & 2.81 & \\
\hline Number of sex partners & & & & 0.003 \\
\hline 1 partner & 1 & & & \\
\hline 2 to 5 & 1.09 & 0.90 & 1.31 & \\
\hline 6 or more & 1.52 & 1.18 & 1.96 & \\
\hline
\end{tabular}

*Prevalence Ratio.

**95\% Confidence Interval.

***P-value obtained by the likelihood ratio test based on the Poisson regression model.

São Luís-Brazil, 2010/2011.

preterm birth, a fact that may have contributed to increased report of abuse suffered by them.

Factors associated with psychological violence against pregnant women have not been routinely analyzed, even when prevalence rates are estimated [8]. Conditions associated with psychological domestic violence or violence on the part of an intimate partner have been frequently analyzed without distinguishing them from other types of violence $[4,6,7,16,19,22-25]$, especially from physical violence $[10,18,20]$, a fact that impairs the comparability of the present result to those of previous studies.

In the Brisa prenatal cohort, EPV and REPV against pregnant women were not associated with skin color, educational level or working and economic variables. Also, they were not associated with characteristics of the intimate partners and heads of family, alcohol abuse or smoking.
EPV was observed more frequently among pregnant women aged 14 to 19 years. Although some studies have pointed out this age range as being of higher risk for violence, a review of the literature has revealed that it was not possible to make this statement since the samples were mostly collected at hospitals or clinics and were not population based [4]. The results of investigations conducted in Michigan and in the municipality of Campinas, Brazil have shown that there was no association between psychological abuse and age of less than 20 years $[8,12]$. Durand and Schraiber [24] also detected no association between psychological violence by intimate partners and age of the pregnant woman. However, these authors did not state whether they excluded pregnant women submitted to physical and/or sexual violence from their analyses.

Pregnant women with an educational level higher than that of their residing intimate partners may have more frequently challenged the norms of gender hierarchy than those with an educational level similar to, or lower than that of their husband/companion. The variable concerning difference in schooling between pregnant women and their residing intimate partners was elaborated for the present investigation and no equivalent variable was detected in publications investigating factors associated with violence against pregnant women [4,6-8,10,12,16-24].

A more usual analysis is that between violence by the intimate partner and women's schooling. Literature reviews consider the results of studies investigating this association to be inconsistent [4] or controversial [7]. As was the case for the Brisa prenatal cohort, several investigations have not detected an association in adjusted analysis $[19,23,24]$. In addition, a cross-sectional study conducted on 3675 pregnant women in the state of Michigan (USA) did not detect an association between psychological abuse and having less than twelve years of study [8]. However, in the municipality of Campinas (São Paulo), Brazilian investigators interviewed 1379 pregnant women and observed a higher risk of psychological violence for pregnant women with up to eight years of study [12].

In the present study we observed that inadequate social affective support/positive social interaction was associated with EPV and REPV. More recently, inadequate social support has started to be investigated as a risk factor for violence against women. A review of the literature yielded results showing a lower occurrence of violence against pregnant women in the presence of an adequate network of social support [4]. The two studies that considered psychological violence as an outcome did not analyze the social support offered to pregnant women $[8,12]$. The affective dimensions (assessed with three questions)/positive social interaction (four questions) investigate the physical demonstrations of love and affection and being 
Table 3 Bivariate analysis of the factors associated with recurrent exclusive psychological violence

\begin{tabular}{llllll}
\hline & \multicolumn{5}{c}{ Recurrent psychological violence } \\
\cline { 2 - 6 } Variables & $\mathbf{n}$ & $\%$ & $\mathrm{PR}^{*}$ & $95 \mathrm{Cl}^{* *}$ & $\mathbf{p}^{* * *}$ \\
\hline Level 1 & & & & &
\end{tabular}

Age range of the pregnant

woman (years, $n=1.078$ )

$\begin{array}{llllll}25 \text { or more } & 612 & 30.3 & 1 & & \\ 14 \text { to } 19 & 125 & 32.8 & 1.08 & 0.82 & 1.42 \\ 20 \text { to } 24 & 341 & 36.6 & 1.21 & 1.01 & 1.45\end{array}$

Age range of the partner (years, $\mathrm{n}=878$ )

\section{5 or more \\ 20 to 24 \\ 14 to 19}

Skin color of the pregnant woman $(n=1.022)$

Crossbred
Black
White
Yellow/Oriental
Schooling of the pregnant
woman ( $\mathrm{n}=1.078$ )
Elementary
Middle
Higher
Schooling of the partner $(\mathrm{n}=862)$
Middle
Higher
Elementary

Remunerated job of the pregnant woman (1.078)

$$
\begin{aligned}
& \text { No } \\
& \text { Yes }
\end{aligned}
$$

Family income in minimum wages $(n=1,047)$

$$
\begin{aligned}
& <1 \\
& 1 \text { to }<3 \\
& 3 \text { to }<5 \\
& \geq 5
\end{aligned}
$$

Brazilian economic class $(n=1.028)$

$$
\begin{aligned}
& C \\
& D / E
\end{aligned}
$$$$
\mathrm{A} / \mathrm{B}
$$

Who is the family head $(n=1.075)$

$$
\begin{aligned}
& \text { Partner } \\
& \text { Pregnant woman }
\end{aligned}
$$$$
\text { Others }
$$

$$
\begin{array}{ccccc}
646 & 29.1 & 1 & & \\
211 & 33.6 & 1.16 & 0.92 & 1.48 \\
21 & 38.1 & 1.31 & 0.75 & 2.29
\end{array}
$$

$$
\begin{array}{ccccc}
691 & 30.1 & 1 & & \\
169 & 34.3 & 1.14 & 0.89 & 1.45 \\
145 & 37.2 & 1.24 & 0.97 & 1.57 \\
17 & 52.9 & 1.76 & 1.11 & 2.79
\end{array}
$$$$
810 \quad 31.1 \quad 1
$$$$
\begin{array}{lllll}
135 & 33.3 & 1.07 & 0.83 & 1.39
\end{array}
$$$$
\begin{array}{lllll}
133 & 41.3 & 1.33 & 1.06 & 1.67
\end{array}
$$

$637 \quad 28.8 \quad 1$

$\begin{array}{lllll}73 & 31.5 & 1.09 & 0.76 & 1.56\end{array}$

$\begin{array}{lllll}152 & 33.5 & 1.16 & 0.90 & 1.49\end{array}$

$$
\begin{array}{ccccc}
566 & 32.1 & 1 & & \\
512 & 33.2 & 0.97 & 0.82 & 1.15
\end{array}
$$

0.380

$$
\begin{array}{ccccc}
40 & 27.5 & 1 & & \\
604 & 30.9 & 1.12 & 0.67 & 1.89 \\
252 & 35.3 & 1.28 & 0.75 & 1.18 \\
151 & 36.4 & 1.32 & 0.77 & 2.29
\end{array}
$$

$$
\begin{array}{ccccc}
692 & 30.2 & 1 & & \\
159 & 36.4 & 1.21 & 0.95 & 1.52 \\
177 & 37.8 & 1.25 & 1.01 & 1.56
\end{array}
$$

$$
\begin{array}{ccccc}
655 & 30.5 & 1 & & \\
109 & 33.9 & 1.11 & 0.83 & 1.48 \\
311 & 36.6 & 1.20 & 0.99 & 1.44
\end{array}
$$

0.048

0.493
Table 3 Bivariate analysis of the factors associated with recurrent exclusive psychological violence (Continued)

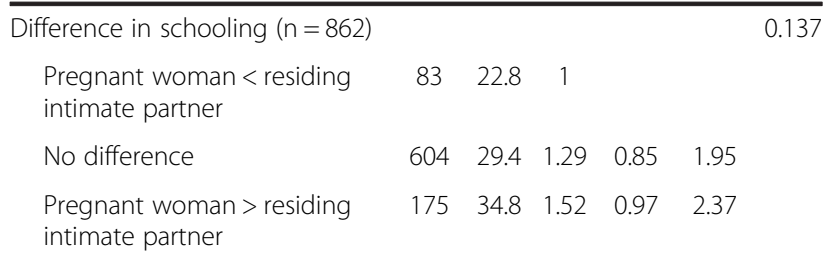

Difference in schooling $(n=862)$ 0.137

Pregnant woman $<$ residing $\quad 83 \quad 22.8 \quad 1$ intimate partner

No difference

$\begin{array}{lllll}604 & 29.4 & 1.29 & 0.85 & 1.95\end{array}$

Pregnant woman > residing $\quad \begin{array}{lllll}175 & 34.8 & 1.52 & 0.97 & 2.37\end{array}$

intimate partner

Difference in occupation $(n=868)$

$\begin{array}{llll}\text { Pregnant woman }<\text { residing } \quad 160 & 23.7 & 1\end{array}$

intimate partner

No difference

$\begin{array}{lllll}565 & 31.8 & 1.34 & 0.99 & 1.82\end{array}$

Pregnant woman > residing $\quad \begin{array}{llllll}143 & 32.1 & 1.35 & 0.94 & 1.95\end{array}$ intimate partner

Level 2

Material dimension of social support $<75$ th percentile $(n=1,078)$

$$
\begin{array}{llllll}
\text { No } & 327 & 24.1 & 1 & & \\
\text { Yes } & 751 & 36.3 & 1.50 & 1.21 & 1.86
\end{array}
$$

Affective dimension/positive social interaction of social support $<75$ th percentile $(n=1,078)$

$$
\text { No }
$$$$
\text { Yes }
$$

$\begin{array}{lll}311 & 23.1 \quad 1\end{array}$

$\begin{array}{lllll}767 & 36.5 & 1.58 & 1.26 & 1.97\end{array}$

Emotional dimension/social support information $<75$ th percentile $(n=1,078)$

$$
\text { No }
$$$$
\text { Yes }
$$

Level 3

Smoking during pregnancy $(\mathrm{n}=1,078)$

$$
\text { No }
$$$$
\text { Yes }
$$

Use of illicit drugs up to 3 months before the current pregnancy $(n=1.078)$

$$
\text { No }
$$$$
\text { Yes }
$$

$1063 \quad 32.4 \quad 1$

$\begin{array}{lllll}12 & 58.3 & 1.79 & 1.10 & 2.92\end{array}$

Alcohol abuse by the pregnant woman during pregnancy

$$
(n=1,076)
$$

$$
\begin{array}{cccccc}
294 & 23.1 & 1 & & \\
784 & 36.2 & 1.57 & 1.25 & 1.968
\end{array}
$$

0.006

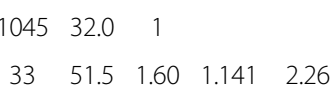

0.018

$$
\text { No }
$$

Yes

$\begin{array}{lll}980 & 31.5 & 1\end{array}$

$\begin{array}{lllll}96 & 43.7 & 1.39 & 1.09 & 1.77\end{array}$

Number of sex partners $(n=1,067)$

$$
1
$$

2 to 5

$\begin{array}{lll}330 & 29.0 \quad 1\end{array}$

$\begin{array}{lllll}632 & 31.8 & 1.09 & 0.89 & 1.34\end{array}$

$\begin{array}{lllll}105 & 45.7 & 1.57 & 1.20 & 2.05\end{array}$

0.002

\footnotetext{
* Prevalence Ratio.

** 95\% Confidence Interval.

***P-value obtained by the likelihood ratio test based on the Poisson regression model.
}

São Luís-Brazil, 2010/2011. 
Table 4 Adjusted analysis of the factors associated with recurrent exclusive psychological violence

\begin{tabular}{|c|c|c|c|c|}
\hline \multirow{2}{*}{$\frac{\text { Variables }(\mathbf{n}=\mathbf{8 6 8})}{\text { Level } 2}$} & \multirow[t]{2}{*}{$\mathrm{PR}^{*}$} & \multicolumn{2}{|c|}{$95 \mathrm{Cl}^{* *}$} & \multirow[t]{2}{*}{$\mathbf{p}^{* * *}$} \\
\hline & & & & \\
\hline $\begin{array}{l}\text { Affective dimension/positive social interaction } \\
\text { of social support }<75 \text { th percentile }\end{array}$ & & & & 0.002 \\
\hline No & 1 & & & \\
\hline Yes & 1.47 & 1.15 & 1.87 & \\
\hline \multicolumn{5}{|l|}{ Level 3} \\
\hline Smoking during pregnancy & & & & 0.065 \\
\hline No & 1 & & & \\
\hline Yes & 1.54 & 0.97 & 2.44 & \\
\hline $\begin{array}{l}\text { Use of illicit drugs up to } 3 \text { months before the } \\
\text { current pregnancy }\end{array}$ & & & & 0.001 \\
\hline No & 1 & & & \\
\hline Yes & 2.28 & 1.40 & 3.71 & \\
\hline Number of sex partners & & & & 0.048 \\
\hline 1 & 1 & & & \\
\hline 2 to 5 & 1.04 & 0.83 & 1.30 & \\
\hline 6 or more & 1.47 & 1.06 & 2.03 & \\
\hline
\end{tabular}

*Prevalence Ratio.

**95\% Confidence Interval.

***P-value obtained by the likelihood ratio test based on the Poisson regression model.

São Luís-Brazil, 2010/2011.

able to count with persons with whom to relax and have fun [14].

The association between violence and use of illicit drugs was also related to EPV and REPV and was detected in various studies analyzed in a review article [4]. The Brazilian study considering psychological violence as the outcome did not investigate the use of illicit drugs during pregnancy [12]. However, the study conducted in the North American state of Michigan revealed a higher risk for this type of violence for women who used illicit drugs (OR 2.17, 95\% CI 1.39; 3.37) [8]. Charles and Perreira [18] did not detect an association between this variable and psychological/physical violence by an intimate partner. Stress preceding pregnancy may have been a justification for the use of illicit drugs [4].

Having had six or more intimate male partners in life was associated with the two outcomes. From this perspective, a systematic review revealed a higher risk of violence for pregnant women with more than five intimate partners during their lives [7]. The only two studies identified that considered psychological violence as the outcome, did not investigate the variable number of intimate partners $[8,12]$. Being aware that his wife/companion/girl friend had other male partners may represent for an intimate partner his lack of control on the body of the woman, resulting in violence [4].
Finally, limitations of the present study should be pointed out, summarized as follows: a) the study was cross-sectional, a design that does not permit to establish cause-effect relationships; b) data about non-residing intimate partners were not collected; and c) this was a convenience sample. As strong points of the study we may mention that this was a population study with a large sample size, which innovated when pregnant women submitted to physical and sexual violence were excluded from the analysis of factors associated with psychological violence. Difficulties in reading and writing have been identified as one of the limitations of the self-administered questionnaire. Furthermore, violence rates tend to be lower when using a self-administered questionnaire [4].

\section{Conclusions}

The rates of psychological violence were higher than those reported in other studies conducted in Brazil and in other countries. There was a greater risk of psychological violence for adolescent women and also for those who challenged hierarchical gender norms since this violence was associated with higher educational level of the interviewee compared to her residing intimate partner and with her having had six or more male intimate partners in life. Pregnant women with an inadequate affective social support/positive social interaction were submitted more frequently to psychological violence and to more numerous episodes of this type of abuse. Unhealthy practices such as the use of illicit drugs during pregnancy and/or up to three months before was a risk factor for psychological violence. There is a need for routine investigation of psychological abuse of pregnant women during their prenatal visits at health care services. Women should also be instructed to demand services of assistance to women victims of psychological violence.

\section{Competing interests}

The authors declare that there are no conflicts of interest regarding political, economic, ideological, religious, academic, intellectual, and personal or any other aspects.

\section{Authors' contributions}

$M R, A S, M A, R B, M B$ and $H B$ were involved in the design and implementation of the study including data collection. All authors have been involved in the analyses, writing, or combinations of these activities and have approved the final manuscript.

\section{Authors' information}

$\mathrm{AS}^{2}$ and $\mathrm{MB}^{7}$ coordinated the Brazilian Birth Cohort Studies of Ribeirão Preto and São Luís (Brisa). $\mathrm{RB}^{2}$ and $\mathrm{HB}^{7}$ coordinated the field activities. $M \mathrm{~A}^{2}$ supervised the data collection. $L R^{3}$ investigates gender violence. $L S^{4}$ coordinated the Multi-country study of the World Health Organization in Brazil.

\section{Acknowledgements}

The authors wish to thank all the women who participated in the research and their relatives. This Research was supported by the Health Ministry, CNPq (Portuguese acronym for the National Research Council), FAPESP (Portuguese acronym for the São Paulo State Research Foundation), and FAPEMA (Portuguese acronym for the Maranhão State Research Foundation). 
The authors are grateful to the Federal University of Maranhão for the support provided.

\section{Author details}

'Department of Medicine III, Federal University of Maranhão, Sao Luis, Brazil. ${ }^{2}$ Department of Public Health, Federal University of Maranhão, Sao Luis, Brazil. ${ }^{3}$ Department of Social Service, Federal University of Maranhão, Sao Luis, Brazil. ${ }^{4}$ Faculty of Medicine, University of São Paulo, São Paulo, Brazil. ${ }^{5}$ Postgraduation Program in Collective Health, Federal University of

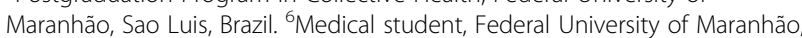
Sao Luis, Brazil. 'Faculty of Medicine of Ribeirão Preto, University of São Paulo, São Paulo, Brazil.

Received: 25 July 2013 Accepted: 4 February 2014

Published: 12 February 2014

\section{References}

1. Brazil: Aspectos conceituais: definindo a violência contra as mulheres. In Politica nacional de enfrentamento à violência contra mulheres. Brasilia: Secretaria Especial de Políticas para as Mulheres; 2011:19-24.

2. Naciones Unidas: Intensificación de los esfuerzos para eliminar todas las formas de violencia contra la mujer. http://www.cinu.mx/minisitio/unete/ A_RES_64_137.pdf.

3. World Health Organization: WHO multi-country study of women's health and domestic violence against women: summary report of initial results on prevalence, health outcomes and women's responses. Geneva: World Health Organization; 2005.

4. Taillieu TL, Brownridge DA: Violence against pregnant women: prevalence, patterns, risk factors, theories, and directions for future research. Aggress Violent Behav 2010, 15:14-35.

5. Campbell J, García-moreno C, Sharps P: Abuse during pregnancy in industrialized and developing countries. Violence Against Women 2004, 10:770-789.

6. Jasinski JL: Pregnancy and domestic violence: a review of the literature. Trauma Violence Abuse 2004, 1:47-64.

7. Shamu S, Abrahams N, Temmerman M, Musekiwa A, Zarowsky C: A systematic review of african studies on intimate partner violence against pregnant women: prevalence and risk factors. PLOS ONE 2011, 6:1-9.

8. Raffo JE, Meghea Cl, Zhu Q, Roman LA: Psychological and physical abuse among pregnant women in a medicaid-sponsored prenatal program. Public Health Nurs 2010, 27:385-398.

9. Reichenheim ME, Moraes $C L$, Hasselmann MH: Equivalência semântica da versão em português do instrumento Abuse Assessment Screen para rastrear a violência contra a mulher grávida. Rev Saude Publica 2000, 34:610-616.

10. Moraes $\mathrm{CL}$, Reichenheim ME: Domestic violence during pregnancy in Rio de Janeiro, Brazil. Int J Gynecol Obstet 2002, 79:269-277.

11. Silva $E P$, Ludermir $A B$, Araújo $T V B$, Valongueiro $S A$ : Freqüência e padrão da violência por parceiro íntimo antes, durante e depois da gravidez. Rev Saude Publica 2011, 45:1044-1053.

12. Audi CAF, Segall-Corrêa AM, Santiago SM, Andrade MGG, Pèrez-Escamila R: Violência doméstica na gravidez: prevalência e fatores associados. Rev Saude Publica 2008, 42:877-885

13. Schraiber $L B$, Latorre MRDO, França Júnior I, Lucas AFP: Validade do instrumento WHO VAW para estimar violência de gênero contra a mulher. Rev Saude Publica 2010, 44:658-666.

14. Griep RH, Chor D, Faerstein E, Werneck GL, Lopes CS: Validade de constructo de escala de apoio social do Medical Outcomes Study adaptada para o português no Estudo Pró-Saúde. Cad Saúde Pública 2005, 21:703-714.

15. Associação Brazileira de Empresas de Pesquisas: Critério de Classificação Econômica Brazil. http://www.abep.org/new/criterioBrasil.aspx.

16. Hoque ME, Hoque M, Kader SB: Prevalence and experience of domestic violence among rural pregnant women in KwaZulu-Natal, South Africa. South Afr J Epidemiol Infect 2009, 24:34-37.

17. Bailey BA, Daugherty RA: Intimate Partner Violence During Pregnancy: incidence and associated health behaviors in a rural population. Matern Child Health J 2007, 11:495-503.

18. Charles P, Perreira KM: Intimate partner violence during pregnancy and 1-year post-partum. J Fam Violence 2007, 22:609-619.
19. Farid $M$, Saleem $S$, Karim MS, Hatcher J: Spousal abuse during pregnancy in Karachi, Pakistan. Int J Gynecol Obstet 2007, 101:141-145.

20. Perales MT, Cripe SM, Lam N, Sanchez SE, Sanchez E, Williams MA: Prevalence, types, and pattern of intimate partner violence among pregnant women in Lima, Peru. Violence Against Women 2009, 15:224-250.

21. Trotter JL, Bogat GA, Levendosky AA: Risk and protective factors for pregnant women experiencing psychological abuse. J Emot Abus 2004, 4:53-70.

22. Yost NP, Bloom SL, Mclntire DD, Leveno KJ: A prospective observational study of domestic violence during pregnancy. Obstet Gynecol 2005, 106:61-65.

23. Castro R, Ruíz A: Prevalencia y severidad de la violencia contra mujeres embarazadas, México. Rev Saude Publica 2004, 38:62-70.

24. Durand JG, Schraiber LB: Violência na gestação entre usuárias de serviços públicos de saúde da Grande São Paulo. Rev Bras Epidemiol 2007, 10:310-322.

25. Silva MA, Falbo Neto GH, Figueiroa JN, Cabral Filho JE: Violence against women: prevalence and associated factors in patients attending a public healthcare service in the Northeast of Brazil. Cad Saúde Pública 2010, 26:264-272.

\section{doi:10.1186/1471-2393-14-66}

Cite this article as: Ribeiro et al:: Psychological violence against pregnant women in a prenatal care cohort: rates and associated factors in São Luís, Brazil. BMC Pregnancy and Childbirth 2014 14:66.

\section{Submit your next manuscript to BioMed Central and take full advantage of:}

- Convenient online submission

- Thorough peer review

- No space constraints or color figure charges

- Immediate publication on acceptance

- Inclusion in PubMed, CAS, Scopus and Google Scholar

- Research which is freely available for redistribution 